\section{(- OPEN ACCESS}

\title{
Body mass index status and peripheral airway obstruction in school-age children: a population- based cohort study
}

\author{
Sandra Ekström ${ }^{1}$ Jenny Hallberg ${ }_{1}^{1,2,3}$ Inger Kull, ${ }^{1,2,3}$ Jennifer L P Protudjer, ${ }^{1,4}$ \\ Per Thunqvist, ${ }^{2,3}$ Matteo Bottai, ${ }^{1}$ Per Magnus Gustafsson, ${ }^{5,6}$ Anna Bergström, ${ }^{1,7}$ \\ Erik Melén ${ }^{1,2,7}$
}

- Additional material is published online only. To view, please visit the journal online (http://dx.doi.org/10.1136/ thoraxjnl-2017-210716).

${ }^{1}$ Institute of Environmental Medicine, Karolinska Institutet, Stockholm, Sweden

${ }^{2}$ Department of Pediatrics,

Sachs' Children and Youth

Hospital, South General Hospital, Stockholm, Sweden

${ }^{3}$ Department of Clinical Science and Education, Karolinska

Institutet, Stockholm, Sweden

${ }^{4}$ The Centre for Allergy

Research, Karolinska Institutet, Stockholm, Sweden

${ }^{5}$ Sahlgrenska Academy, University of Gothenburg, Gothenburg, Sweden ${ }^{6}$ Department of Paediatrics, Central Hospital, Skövde,

Sweden

${ }^{7}$ Centre for Occupational and Environmental Medicine, Stockholm County Council, Stockholm, Sweden

\section{Correspondence to}

Ms Sandra Ekström, Institute of Environmental Medicine, Karolinska Institutet, Stockholm 171 77, Sweden;

Sandra.Ekstrom@ki.se

$A B$ and $E M$ contributed equally.

Received 30 June 2017

Revised 18 December 2017

Accepted 8 January 2018

Published Online First

29 January 2018

Check for updates

To cite: Ekström $S$,

Hallberg J, Kull I, et al. Thorax 2018;73:538-545.

\section{ABSTRACT}

Background Few large prospective studies have investigated the impact of body mass index (BMI) on lung function during childhood.

Methods Using data collected between 2002 and 2013, we analysed associations between BMI status and lung function (assessed by spirometry) from 8 to 16 years, as well as cross-sectional associations with small airway function (impulse oscillometry) at 16 years in the BAMSE cohort $(n=2889)$. At 16 years, cross-sectional associations with local and systemic inflammation were investigated by analysing $\mathrm{FE}_{\mathrm{NO}}$, blood eosinophils and neutrophils.

Results Overweight and obesity at 8 years were associated with higher FVC, but lower FEV, /FVC ratio at 8 and 16 years. In boys, but not girls, obesity at 8 years was associated with a further reduction in $\mathrm{FEV}_{1} / \mathrm{FVC}$ between 8 and 16 years. In cross-sectional analyses, overweight and obesity were associated with higher frequency dependence of resistance $\left(R_{5-20}\right)$ and larger area under the reactance curve $\left(A X^{0.5}\right)$ at 16 years. Increased blood neutrophil counts were seen in overweight and obese girls, but not in boys. No association was found between BMI status and $\mathrm{FE}_{\mathrm{NO}}$. Persistent, but not transient, overweight/obesity between 8 and 16 years was associated with higher $\mathrm{R}_{5-20}$ and $A X^{0.5}$ and lower FEV, /FVC $(-2.8 \%(95 \% \mathrm{Cl}-4.1$ to $-1.2)$ in girls and $-2.7 \%(95 \% \mathrm{Cl}-4.4$ to -1.1$)$ in boys $)$ at 16 years, compared with persistent normal weight. Conclusion In childhood and adolescence, overweight and obesity, particularly persistent overweight, were associated with evidence of airway obstruction, including the small airways.

\section{INTRODUCTION}

Obesity is a global health challenge associated with several adverse health consequences. ${ }^{1}$ The respiratory system may be adversely affected due to low-grade systemic inflammation and increased mechanical load of the truncal fat on the chest resulting from obesity. ${ }^{2}$ Most studies in children have observed an association between high body mass index (BMI) or waist circumference and reduced ratio between $\mathrm{FEV}_{1}$ and $\mathrm{FVC}$, but unaffected or higher $\mathrm{FEV}_{1}$ and FVC. ${ }^{4-12}$ This was also confirmed in a recent meta-analysis which reported a $2.4 \%(-3.0 ;-1.8)$ lower $\mathrm{FEV}_{1} / \mathrm{FVC}$ in

\section{Key messages}

What is the key question?

- Are overweight and obesity associated with reduced lung function, including small airway obstruction in school-age and adolescence?

What is the bottom line?

- Both overweight and obesity, and particularly persistent overweight, in childhood and adolescence are associated with physiological signs of airway obstruction, which also involves the peripheral airways.

Why read on?

- This population-based longitudinal study is the first to investigate the association between overweight/obesity and peripheral airway obstruction among adolescents.

overweight or obese, compared with normal weight children. ${ }^{13}$ These results indicate that childhood overweight and obesity might be associated with airway obstruction, although lung volume and flow may be high or normal. In another recent analysis including six cohorts of children, Forno et $a l^{14}$ provided new physiological insights by showing that overweight and obesity were associated with dysanapsis (incongruence between growth of the lungs and the airways, characterised by abnormal $\mathrm{FEV}_{1} / \mathrm{FVC}$ despite normal $\mathrm{FEV}_{1}$ and $\mathrm{FVC}$ ) in both children with and without asthma. The authors discuss that childhood obesity results in anatomical and/or developmental airflow obstruction that are not related to airway inflammation, although measurements using other methods are required to confirm this hypothesis. ${ }^{14}$ In addition, the role of local or systemic inflammatory mechanisms needs to be explored further.

The majority of studies linking obesity and lung function in children are based on spirometry, which mostly reflects large airway function. ${ }^{15}$ Impulse oscillometry (IOS) is an effort-independent technique to assess lung resistance and reactance, with potential to discriminate between peripheral and central airway function. ${ }^{16}$ Small airway function has been associated with asthma symptoms such as dyspnoea, impaired asthma control and 
health-related quality of life. ${ }^{17}{ }^{18}$ However, it is still unknown how overweight and obesity affect the small airways in children and adolescents.

Moreover, the temporal relation between obesity and lung function development is unclear, as most evidence linking childhood obesity and lung function is cross-sectional. In the Dutch PIAMA birth cohort, persistent but not transient high BMI between 8 and 12 years was associated with lower $\mathrm{FEV}_{1} / \mathrm{FVC}$ among 1090 children at 12 years. ${ }^{19}$ In the present study, we extend these temporal analyses on overweight duration up to 16 years.

The main aim of the present study was to investigate the longitudinal association between BMI status between school-age and adolescence in relation to lung function, including small airway function, in a large population-based prospective cohort. To gain insight into potential mechanisms, a secondary aim was to investigate whether overweight and obesity are associated with airway and systemic inflammation biomarkers.

\section{METHOD}

\section{Study population and study design}

The study population includes children from the prospective birth cohort BAMSE, previously described in detail elsewhere. $^{2021}$ The BAMSE study includes 4089 children from the northwestern and central parts of Stockholm, Sweden $(75 \%$ of eligible children in the catchment area). Non-responders and children who were actively excluded from the baseline cohort were similar to the study population in terms of parental allergic disease and pet keeping; however, the proportion of parental smoking was somewhat higher. ${ }^{21}$ The children were subsequently followed from around 2 months of age, with repeated parental questionnaires on symptoms of allergic disease as well as on lifestyle and environmental exposures. At 16 years, the adolescents themselves also answered a questionnaire. The parental response rate was $84 \%$ at 8 years and $78 \%$ and $76 \%$ for the parent and adolescent, respectively, at 16 years.

\section{Measurements of exposures and outcomes}

When the children were approximately 8 and 16 years, clinical investigations with measurements of height and weight were performed by trained nurses using standard protocols among 2620 (64\%) and 2599 (64\%) of the children, respectively. BMI was calculated as weight in kilograms divided by height in metres squared $\left(\mathrm{kg} / \mathrm{m}^{2}\right)$ and categorised into thinness, normal weight, overweight and obesity per gender-specific and age-specific cut-off values proposed by the International Obesity Task Force. ${ }^{22}$ Lung function was measured by spirometry at 8 years using a 2200 Pulmonary Function Laboratory (SensorMedics, Anaheim, California, USA) and by IOS followed by spirometry at 16 years using a Jaeger MasterScreen-IOS system (Carefusion Technologies, San Diego, California, USA). ${ }^{23}$ All participants performed repeated maximal expiratory flow volume (MEFV) measurements. The highest values of FVC and FEV were extracted and used for analysis, provided that the subject's effort was accepted as being maximal by the test leader, that the MEFV curve passed visual quality inspection and that the two highest $\mathrm{FEV}_{1}$ and $\mathrm{FVC}$ readings were reproducible according to American Thoracic Society/ European Respiratory Society (ATS/ERS) criteria $(n=1832$ at 8 years and $n=2056$ at 16 years). ${ }^{24} \mathrm{FEV}_{1} / \mathrm{FVC}$ ratios were calculated and expressed as percentages. Dysanapsis was defined as normal to high FVC z-score $(\geq 0.674)$, normal $\mathrm{FEV}_{1}$ z-score $(\geq 1.645)$ and low $\mathrm{FEV}_{1} /$ FVC $(<80 \%) .{ }^{14}$
The IOS measurements have been described elsewhere. ${ }^{23} 25$ Briefly, external pressure impulses are superimposed during tidal breathing at frequencies between 5 and $35 \mathrm{~Hz}$. Higher frequencies are reaching the large airways, whereas lower frequencies travel deeper into the lung. Participants wore a nose clip and were instructed to tightly seal their lips around the mouthpiece and support their cheeks with their hands. After quality inspection, the mean value of resistance between $5 \mathrm{~Hz}$ and $20 \mathrm{~Hz}\left(\mathrm{R}_{5-20}\right)$ and the square root of the area under the reactance curve $\left(\mathrm{AX}^{0.5}\right)$ were used for analyses $(n=2452)$. Resistance is defined as the ratio of the pressure drop over an airway segment, ${ }^{25}$ whereas reactance can be viewed as the rebound resistance of the lung. ${ }^{16}$ Measurements of $\mathrm{FE}_{\mathrm{NO}}$ were performed at an expiratory flow of $50 \mathrm{~mL} / \mathrm{s}\left(\mathrm{FE}_{\mathrm{NO}} 50\right)$, using an online chemiluminescent (CLD88) analyser (Eco Medics AG, Duernten, Switzerland) according to ERS/ATS guidelines $(n=2087) .{ }^{26}$ Peripheral blood samples $(n=2558)$ were analysed for eosinophil and neutrophil cell counts at 16 years (Department of Clinical Chemistry, Karolinska University Hospital, Stockholm, Sweden).

Asthma symptoms (current wheeze and breathing difficulties during exercise) and medication use were reported by the parent at 8 years and by the adolescent at 16 years. The definitions of these variables are described in the online supplement. The study was approved by the Regional Ethical Review Board in Stockholm.

\section{Statistical analyses}

Associations between BMI status and lung function (spirometry and IOS) were considered as main analyses, whereas associations with $\mathrm{FE}_{\mathrm{NO}}$, eosinophil/neutrophil cell counts and asthma symptoms were considered as secondary analyses. Differences between children who were included and excluded from the study population were analysed by the t-test (continuous variables) and by the $\chi^{2}$ test (categorical variables). Associations between BMI status at 8 years (using normal weight as referent) and spirometry up to 16 years were analysed longitudinally by mixed-effects linear regression with a random intercept, an unstructured correlation matrix and restricted maximum likelihood estimation. Mixed-effect models for longitudinal data take the correlation between repeated measurements on the same individual into account. An interaction term between BMI status and the time indicator variable was incorporated into the model to estimate age-specific associations at 8 and 16 years and changes in lung function between 8 and 16 years. For outcomes collected at 16 years only, ordinary linear regression (continuous variables) and logistic regression analysis (categorical variables) were used. IOS, $\mathrm{FE}_{\mathrm{NO}}$ and eosinophil/neutrophil cell count were analysed on the median using quantile regression, due to non-normally distributed data. ${ }^{27}$

Analyses were stratified by gender, and any potential interaction between BMI status and gender, as well as with wheeze, was tested by the Wald test using an interaction term between overweight and gender and overweight and wheeze, respectively, in the statistical model. Results were expressed as z-scores using the Global Lung Initiative reference values for $\mathrm{FEV}_{1}$ and $\mathrm{FVC}^{28}$ and as height-adjusted and age-adjusted per cent for $\mathrm{FEV}_{1} / \mathrm{FVC}$, to facilitate interpretation. As a sensitivity analysis, $\mathrm{FEV}_{1} / \mathrm{FVC}$ was also analysed as z-scores to ensure that the results were comparable. IOS results were not transformed to z-scores, due to lack of reference values, but adjusted for height and age. Overweight and obesity were sometimes analysed together due to low numbers in each subgroup. 
Covariates were identified from previous literature and evaluated as potential confounders in the present study by adding them one by one to the crude model with $\mathrm{FEV}_{1} / \mathrm{FVC}$ as the outcome for girls and boys separately. The tested variables were parental allergic disease, maternal smoking during pregnancy and/or in infancy, socioeconomic status at baseline, birth weight, gestational age, maternal BMI in early pregnancy, breastfeeding $\geq 4$ months, pubertal status at 12 and 16 years, physical activity at 16 years and self-reported smoking at 16 years. All these variables affected the estimate by less than $10 \%$ and were therefore not included in the final model, with the exception of the analyses on $\mathrm{FE}_{\mathrm{NO}}$ which were adjusted for smoking at 16 years. However, an adjusted analysis including key potential confounding factors (socioeconomic status at baseline, maternal smoking during pregnancy and/or in infancy and pubertal status at 16 years) was also performed for completeness. In order to investigate whether asthma or asthma symptoms could explain the association between BMI status and lung function, separate cross-sectional analyses were also performed with adjustment for asthma and wheeze. Definitions of covariates are described in the online supplement.

Children were included in the present analyses if spirometry and BMI status were available at 8 or 16 years or if IOS and BMI status were available at 16 years $(n=2889)$; however, the number of children with available data for the different outcomes varied. Children with missing data on one of the exposures, outcomes or covariates were not included in that specific analysis, except for the mixed-effect models analyses which require data on the outcome from at least one time point (see exact number in each table). All analyses were performed using the statistical software STATA V.13 (StataCorp).

\section{RESULTS}

\section{Descriptive results on exposure and outcomes}

Only small differences were observed between children who were included in the study population $(n=2889)$ compared with children who did not fulfil the inclusion criteria $(n=1199$, online supplementary table 1 ).

At 8 years, $17.8 \%$ of the girls and $15.2 \%$ of the boys were overweight, and another $3.8 \%$ and $3.4 \%$ were obese (table 1). The prevalence of overweight and obesity declined to $11.7 \%$ and $2.0 \%$, respectively, in girls at 16 years, but was rather stable in boys. The majority of children with obesity were moderately obese, and less than $1 \%$ fulfilled the definition of obesity class II (which corresponds to BMI $35 \mathrm{~kg} / \mathrm{m}^{2}$ at 18 years). At 16 years, $15.9 \%$ of the girls and $10.0 \%$ of the boys reported wheezing in the past year, and $15.1 \%$ of the girls and $18.7 \%$ of the boys had had a doctor's diagnosis of asthma.

\section{Longitudinal associations between BMI status at 8 years and lung function from 8 to 16 years}

Figure 1 shows the results from the mixed-effect models analyses of the longitudinal association between BMI status at 8 years and lung function up to 16 years. Both overweight and obesity were associated with higher FVC (eg, SD 0.66 (95\% CI 0.35 to 0.97 ) and SD 0.49 (95\% CI 0.11 to 0.87$)$ in obese, compared with normal weight girls and boys, respectively, at 16 years). Overweight was also associated with higher $\mathrm{FEV}_{1}$ in boys at 8 and 16 years and in girls at 16 years, and obesity was associated with higher $\mathrm{FEV}_{1}$ in girls at 8 and 16 years and in boys at 8 years. However, overweight and obesity were associated with lower $\mathrm{FEV}_{1} / \mathrm{FVC}$ (eg, $-2.0 \%$ (95\% CI $-4.0 \%$ to $0.0 \%$ ) and $-3.8 \%$ $(95 \%$ CI $-6.3 \%$ to $-1.2 \%)$ in obese, compared with normal weight girls and boys, respectively, at 16 years). Thinness was associated with lower FVC and $\mathrm{FEV}_{1}$, but there were no significant associations between thinness and $\mathrm{FEV}_{1} / \mathrm{FVC}$. Analysing $\mathrm{FEV}_{1} / \mathrm{FVC}$ by z-score instead of percentage had no impact on the interpretation of results (results not shown). Additional adjustments for maternal smoking during pregnancy and/or infancy, socioeconomic status at baseline and pubertal status at 16 years did not have any major impact on the observed associations (results not shown).

Changes in lung function between 8 and 16 years were analysed in relation to BMI status at 8 years by estimating the interaction between BMI and age. In males, obesity was associated with a further reduction in $\mathrm{FEV}_{1} / \mathrm{FVC}$ between 8 and 16 years, whereas there was no association between overweight and change in $\mathrm{FEV}_{1} / \mathrm{FVC}$. In females, overweight, but not obesity, was associated with a small positive change in $\mathrm{FEV}_{1}$ and FVC between 8 and 16 years, whereas no association was observed between overweight or obesity and change in $\mathrm{FEV}_{1} / \mathrm{FVC}$.

In addition, we analysed the cross-sectional association between BMI status and dysanapsis at 16 years. Out of 2052 participants with available information on $\mathrm{FEV}_{1}, \mathrm{FVC}$ and $\mathrm{BMI}$ status at 16 years, 180 children (8.8\%) fulfilled the definition of dysanapsis. Dysanapsis was more common among overweight/ obese children compared with normal weight children (OR 1.61 (95\% CI 0.90 to 2.86) in girls and 1.77 (95\% CI 1.08 to 2.92 ) in boys) (thinness excluded, $n=1641$ ).

\section{Associations between BMI status at 8 and 16 years and small airway impairment at 16 years}

BMI status at 8 and 16 years was further analysed in relation to small airway function at 16 years (table 2). Cross-sectional analyses at 16 years showed that overweight and obesity were associated with higher $\mathrm{AX}^{0.5}$ and $\mathrm{R}_{5-20}$ at 16 years (table 2), with stronger associations in overweight girls, compared with boys ( $\mathrm{P}$ value for interaction $=0.03$ for $\mathrm{R}_{5-20}$ and 0.004 for $\mathrm{AX}^{0.5}$ ). Thinness was associated with lower $\mathrm{R}_{5-20}$.

Analysing BMI status at 8 years in relation to IOS at 16 years resulted in somewhat weaker associations, compared with BMI at 16 years. Overweight in girls and obesity in boys at 8 years were associated with higher $\mathrm{R}_{5-20}$ and $\mathrm{AX}^{0.5}$ at 16 years.

\section{Associations between BMI status and asthma symptoms at 16 years}

Overweight (including obesity) was significantly associated with asthma symptoms (wheeze and breathing difficulties during exercise), doctor's diagnosis of asthma and asthma medication in cross-sectional analyses at 16 years among girls (online supplementary table 2), whereas weaker associations were seen for boys.

Categorisation of children into groups of overweight (including obesity) and/or wheeze at 16 years (figure 2) showed that overweight and wheeze were both independently associated with lower $\mathrm{FEV}_{1} / \mathrm{FVC}$ at 16 years $(-2.5 \%$ (95\% CI $-3.6 \%$ to $-1.3 \%)$ and $-2.6 \%$ (95\% CI $-3.7 \%$ to $-1.4 \%)$, respectively, among girls and $-2.0 \%(95 \% \mathrm{CI}-3.2 \%$ to $-0.8 \%)$ and $-3.1 \%$ (95\% CI $-4.6 \%$ to $-1.5 \%)$, respectively, among boys). Concomitant overweight and wheeze were associated with further reduction in $\mathrm{FEV}_{1} / \mathrm{FVC}(-3.8 \%$ (95\% CI $-5.9 \%$ to $-1.8 \%)$ in girls and $-3.6 \%$ (95\% CI $-6.3 \%$ to $-0.94 \%)$ in boys), but there was no significant interaction between overweight and wheeze.

As BMI and asthma were associated, we aimed to investigate whether asthma or asthma symptoms could explain the association between overweight/obesity and lung function. 
Table 1 Anthropometric and lung function characteristics among children in the 8-year and 16-year examination in the BAMSE cohort ( $\mathrm{n}=2889)$

\begin{tabular}{|c|c|c|c|c|c|c|c|c|c|c|c|c|}
\hline & \multicolumn{6}{|c|}{8 years } & \multicolumn{6}{|c|}{16 years } \\
\hline & \multicolumn{3}{|l|}{ Girls } & \multicolumn{3}{|l|}{ Boys } & \multicolumn{3}{|l|}{ Girls } & \multicolumn{3}{|l|}{ Boys } \\
\hline & $n^{*}$ & Mean & SD & $\mathrm{n}^{*}$ & Mean & SD & $\mathrm{n}^{*}$ & Mean & SD & $\mathrm{n}^{*}$ & Mean & SD \\
\hline \multirow[t]{2}{*}{ Age, year } & 1216 & 8.3 & 0.5 & 1331 & 8.6 & 0.5 & 1323 & 16.7 & 0.4 & 1241 & 16.7 & 0.4 \\
\hline & $\mathrm{n}^{*}$ & $\mathrm{nt}$ & $\%$ & $\mathrm{n}^{*}$ & $\mathrm{n} \dagger$ & $\%$ & $\mathrm{n}^{*}$ & $\mathrm{n} \dagger$ & $\%$ & $\mathrm{n}^{*}$ & $\mathrm{nt}$ & $\%$ \\
\hline \multicolumn{13}{|l|}{ BMI status $\ddagger$} \\
\hline Thinness & 1213 & 37 & 3.1 & 1226 & 30 & 2.5 & 1321 & 97 & 7.3 & 1241 & 84 & 6.8 \\
\hline Normal weight & 1213 & 914 & 75.4 & 1226 & 968 & 79.0 & 1321 & 1043 & 79.0 & 1241 & 927 & 74.7 \\
\hline Overweight & 1213 & 216 & 17.8 & 1226 & 186 & 15.2 & 1321 & 155 & 11.7 & 1241 & 190 & 15.3 \\
\hline \multirow[t]{2}{*}{ Obesity§ } & 1213 & 46 & 3.8 & 1226 & 42 & 3.4 & 1321 & 26 & 2.0 & 1241 & 40 & 3.2 \\
\hline & $\mathrm{n}^{*}$ & Mean & SD & $\mathrm{n}^{*}$ & Mean & SD & $\mathrm{n}^{*}$ & Mean & SD & $\mathrm{n}^{*}$ & Mean & SD \\
\hline $\mathrm{FEV}_{1}, \mathrm{ml}$ & 920 & 1732.1 & 256.6 & 912 & 1820.5 & 279.9 & 1121 & 3480.5 & 445.6 & 933 & 4491.4 & 650.2 \\
\hline $\mathrm{FEV}_{1}, \mathrm{z}$-score & 919 & 0.47 & 0.94 & 912 & 0.36 & 0.93 & 1119 & -0.04 & 0.91 & 933 & -0.04 & 0.97 \\
\hline $\mathrm{FVC}, \mathrm{ml}$ & 920 & 1987.7 & 294.1 & 912 & 2144.5 & 339.7 & 1121 & 4033.2 & 522.8 & 933 & 5380.4 & 777.1 \\
\hline FVC, z-score & 920 & 0.62 & 0.90 & 912 & 0.56 & 0.91 & 1119 & 0.15 & 0.89 & 933 & 0.15 & 0.96 \\
\hline \multirow[t]{2}{*}{$\mathrm{FEV}_{1} / \mathrm{FVC}, \%$} & 920 & 87.3 & 5.3 & 912 & 85.2 & 5.9 & 1121 & 86.5 & 6.1 & 933 & 83.8 & 6.6 \\
\hline & & & & & & & $\mathrm{n}^{*}$ & Median & IQR & $\mathrm{n}^{*}$ & Median & $\mathrm{IQR}$ \\
\hline $\mathrm{R}_{5-20}\left(\mathrm{~Pa} \cdot \mathrm{L}^{-1} \cdot \mathrm{s}\right)$ & & & & & & & 1260 & 20.0 & 55.0 & 1191 & 15.0 & 45.0 \\
\hline$A X^{0.5}\left(\mathrm{~Pa} \cdot \mathrm{L}^{-1}\right)^{0.5}$ & & & & & & & 1260 & 16.4 & 5.8 & 1190 & 12.6 & 5.0 \\
\hline $\mathrm{FE}_{\mathrm{NO}}(\mathrm{ppb})$ & & & & & & & 1044 & 14.0 & 10.1 & 1015 & 17.5 & 13.8 \\
\hline Blood eosinophils ( $10^{9}$ cells/L) & & & & & & & 1225 & 0.1 & 0.1 & 1168 & 0.2 & 0.1 \\
\hline \multirow[t]{2}{*}{ Blood neutrophils ( $10^{9}$ cells/L) } & & & & & & & 1225 & 3.5 & 1.6 & 1168 & 3.0 & 1.4 \\
\hline & $\mathrm{n}^{*}$ & $\mathrm{nt}$ & $\%$ & $\mathrm{n}^{*}$ & $\mathrm{n} \dagger$ & $\%$ & $\mathrm{n}^{*}$ & $\mathrm{n} \dagger$ & $\%$ & $\mathrm{n}^{*}$ & $\mathrm{nt}$ & $\%$ \\
\hline Current wheezeף & 1410 & 125 & 8.9 & 1362 & 167 & 12.3 & 1362 & 216 & 15.9 & 1267 & 127 & 10.0 \\
\hline $\begin{array}{l}\text { Breathing difficulties during exercise } \emptyset_{* *} \\
\text {, }\end{array}$ & 1413 & 64 & 4.5 & 1273 & 98 & 7.2 & 1392 & 409 & 29.4 & 1298 & 272 & 21.0 \\
\hline Doctor's diagnosis of asthmat† & 1394 & 146 & 10.5 & 1349 & 196 & 14.5 & 1397 & 211 & 15.1 & 1337 & 250 & 18.7 \\
\hline Asthma medicationף, & 1415 & 83 & 5.9 & 1367 & 127 & 9.3 & 1391 & 113 & 8.1 & 1309 & 100 & 7.6 \\
\hline
\end{tabular}

*Number with available data.

tNumber of exposed/cases.

¥Cole TJ, Lobstein T. Extended International (IOTF) body mass index cut-offs for thinness, overweight and obesity. Paediatric Obesity 7; $284-94$.

$\S A$ t 8 years, 11 girls $(0.9 \%)$ and 5 boys $(0.4 \%)$ fulfilled the definition of obesity class II (corresponds to BMI $35 \mathrm{~kg} / \mathrm{m}^{2}$ at 18 years. At 16 years, 7 girls $(0.5 \%)$ and 5 boys $(0.4 \%)$

fulfilled this definition.

IAnswered by the parent at 8 years and by the adolescent at 16 years.

${ }^{*}$ Doctor's diagnosis up to 8 and 16 years, respectively.

††Defined as wheezing or raspy breathing at 8 years and as wheezy or raspy breathing, difficulty breathing or troublesome cough at 16 years.

$\ddagger \neq$ Inhaled steroids occasionally or regularly (as steroids only or as a combination of inhaled steroids and long-acting beta-agonist).

$A X^{0.5}$, area under the reactance curve; BMI, body mass index; $R$, frequency dependence of resistance.

We therefore performed separate cross-sectional analyses on overweight/obesity and lung function at 16 years, adjusted for wheeze and asthma. Neither asthma nor wheeze was found to have any major impact on the estimates between overweight/ obesity and lung function (results not shown).

\section{Associations between BMI status and local and systemic inflammatory biomarkers}

Subsequently, we analysed cross-sectional associations between BMI status and local and systemic inflammatory biomarkers at 16 years. There was no association between $\mathrm{BMI}$ status and $\mathrm{FE}_{\mathrm{NO}}$ (online supplementary table 3). Overweight and obesity were associated with higher blood neutrophil cell count in girls $(\mathrm{P}=0.03$ and 0.007 , respectively), but the association was weaker and non-significant in boys (online supplementary table 3). Obesity, but not overweight, was associated with somewhat higher blood eosinophil cell count in girls $(\mathrm{P}<0.001)$, whereas no association was observed in boys (online supplementary table 3).

Associations between change in BMI status between 8 and 16 years and lung function and inflammation at 16 years

Figure 3 shows the association between BMI status, analysed longitudinally between 8 and 16 years, and $\mathrm{FEV}_{1} / \mathrm{FVC}$ at 16 years. Mean (SD) BMI for each group is presented in online supplementary table 4. Persistent, but not transient, overweight (including obesity) between 8 and 16 years was associated with lower $\mathrm{FEV}_{1} / \mathrm{FVC}$ at 16 years, among girls $(-2.8 \%(95 \% \mathrm{CI}-4.1 \%$ to $-1.2 \%))$ and boys $(-2.7 \%(95 \%$ CI $-4.4 \%$ to $-1.1 \%)$ ), compared with persistent normal weight. Overweight at 16 years, but not 8 years, was borderline associated with lower $\mathrm{FEV}_{1} / \mathrm{FVC}$. Overweight at 16 years, but not 8 years, and persistent overweight were further associated with higher $\mathrm{AX}^{0.5}$ and $\mathrm{R}_{5-20}$ (online supplementary 
Girls

$\mathrm{FEV}_{1}$ z-score

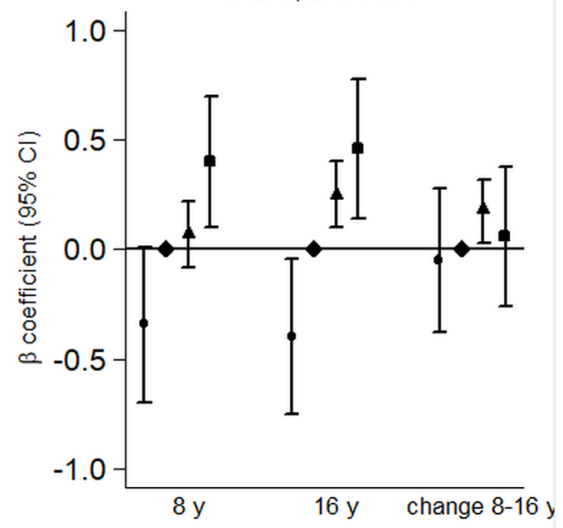

FVC z-score

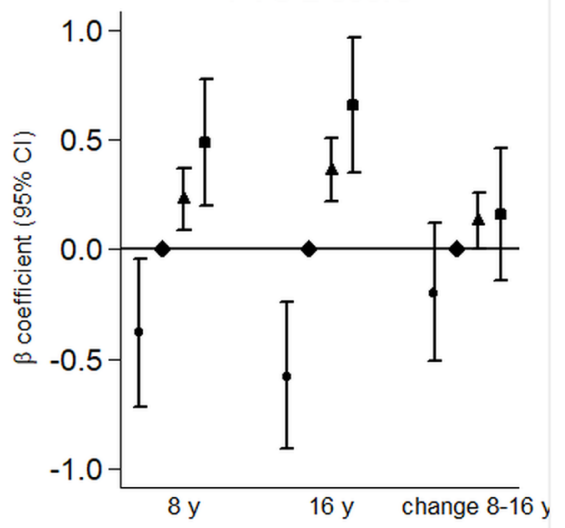

$\mathrm{FEV}_{1} / \mathrm{FVC}(\%)$

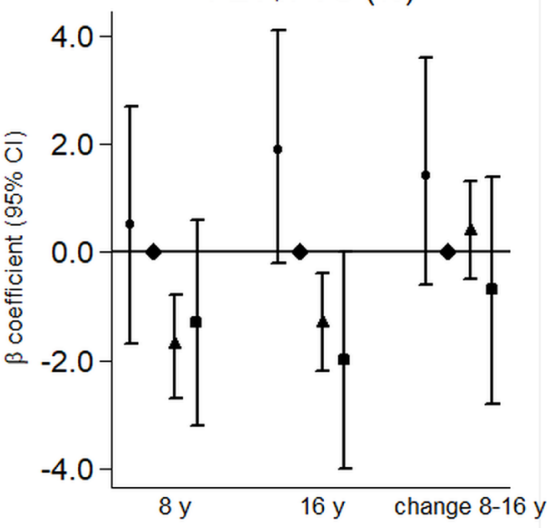

Boys
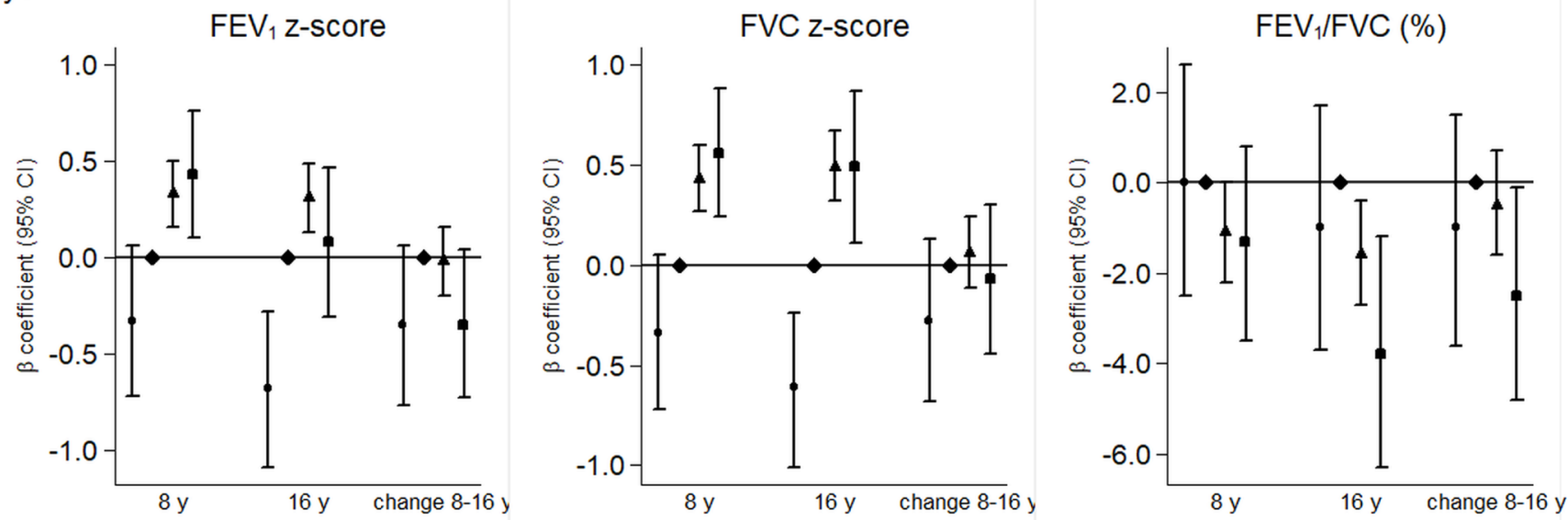

Figure 1 Association between BMI status (thinness $(\boldsymbol{\bullet})$, normal weight ( $\bullet$, referent), overweight $(\mathbf{\Delta})$ and obesity $(\boldsymbol{\square})$ ) at 8 years and lung function ( $\mathrm{FEV}_{1}$ ( $\mathrm{z}$-scores), FVC (z-scores) and FEV $\left./ \mathrm{FVC}(\%)\right)$ up to 16 years. $\beta$-Coefficients and $95 \%$ Cls were estimated using mixed-effect models $(\mathrm{n}=1158$ girls with 1827 observations and $n=1135$ boys with 1689 observations). Changes in lung function between 8 and 16 years ('change 8-16 years') were estimated by the interaction between BMI status and the time indicator variable. BMI, body mass index.

Table 2 Associations between BMI status at 8 and 16 years and impulse oscillometry 16 years ( $n=1016$ girls at 8 years and 1258 girls at 16 years, $\mathrm{n}=999$ boys at 8 years and 1191 boys at 16 years)

\begin{tabular}{|c|c|c|c|c|c|c|c|c|c|c|c|c|}
\hline & \multicolumn{6}{|c|}{$\mathrm{R}_{5-20}\left(\mathrm{~Pa} \cdot \mathrm{L}^{-1} \cdot \mathrm{s}\right)$} & \multicolumn{6}{|c|}{$\mathrm{AX}^{0.5}\left(\mathrm{~Pa} \cdot \mathrm{L}^{-1}\right)^{0.5}$} \\
\hline & \multicolumn{3}{|l|}{ Girls } & \multicolumn{3}{|l|}{ Boys } & \multicolumn{3}{|l|}{ Girls } & \multicolumn{3}{|l|}{ Boys } \\
\hline & $\beta^{*}$ & $95 \% \mathrm{Cl}$ & $P$ value & $\beta^{*}$ & $95 \% \mathrm{Cl}$ & $P$ value & $\beta^{*}$ & $95 \% \mathrm{Cl}$ & $P$ value & $\beta^{*}$ & $95 \% \mathrm{Cl}$ & $P$ value \\
\hline \multicolumn{13}{|l|}{ BMI status 8 years } \\
\hline Thinness & 8.6 & -10.0 to 27.2 & 0.36 & -8.8 & -25.2 to 7.5 & 0.29 & 0.8 & -1.0 to 2.7 & 0.36 & -1.0 & -2.6 to 0.6 & 0.21 \\
\hline Normal weight & \multicolumn{3}{|c|}{ Referent } & \multicolumn{3}{|c|}{ Referent } & \multicolumn{3}{|c|}{ Referent } & \multicolumn{3}{|c|}{ Referent } \\
\hline Overweight & 10.9 & 2.0 to 19.7 & 0.02 & 6.8 & -0.57 to 14.1 & 0.07 & 1.1 & 0.3 to 2.0 & 0.009 & 0.4 & -0.3 to 1.2 & 0.23 \\
\hline Obesity & 11.6 & -8.2 to 31.3 & 0.25 & 31.7 & 16.7 to 46.7 & $<0.001$ & -0.4 & -2.4 to 1.5 & 0.65 & 2.3 & 0.8 to 3.8 & 0.003 \\
\hline \multicolumn{13}{|l|}{ BMI status 16 years } \\
\hline Thinness & -15.9 & -25.8 to -6.0 & 0.002 & -12.9 & -21.9 to -3.9 & 0.005 & -0.4 & -1.4 to 0.6 & 0.42 & -0.3 & -1.2 to 0.7 & 0.58 \\
\hline Normal weight & \multicolumn{3}{|c|}{ Referent } & \multicolumn{3}{|c|}{ Referent } & \multicolumn{3}{|c|}{ Referent } & \multicolumn{3}{|c|}{ Referent } \\
\hline Overweight & 32.7 & 24.5 to 40.9 & $<0.001$ & 22.3 & 16.1 to 28.5 & $<0.001$ & 3.1 & 2.3 to 3.9 & $<0.001$ & 1.6 & 0.9 to 2.2 & $<0.001$ \\
\hline Obesity & 56.8 & 38.3 to 75.4 & $<0.001$ & 47.8 & 34.9 to 60.7 & $<0.001$ & 3.1 & 1.3 to 4.9 & 0.001 & 3.5 & 2.2 to 4.8 & $<0.001$ \\
\hline
\end{tabular}

*Represent median difference in outcome compared with the reference group, calculated by linear regression on the median adjusted for age and height. $A X^{0.5}$, area under the reactance curve; $B M I$, body mass index; $R$, frequency dependence of resistance. 


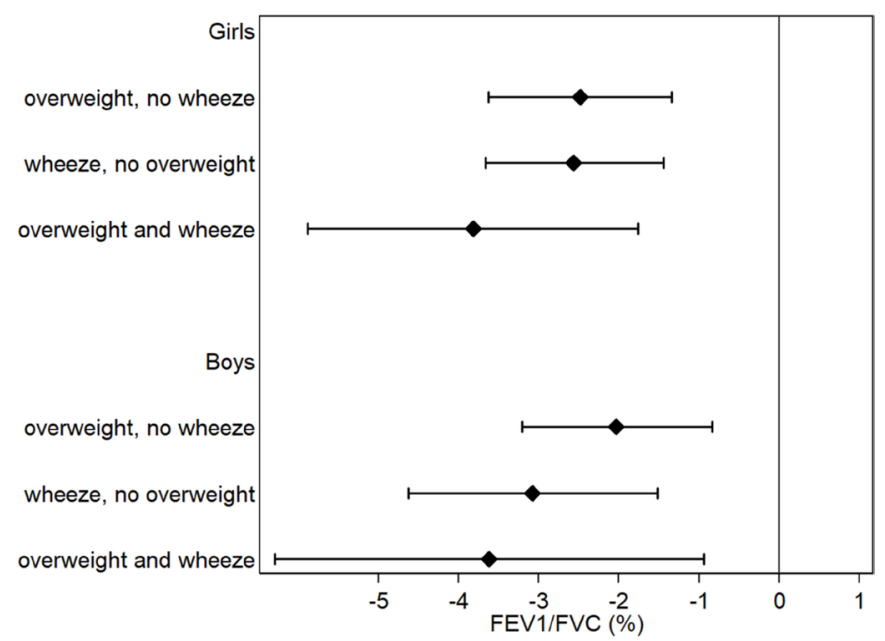

Figure 2 Association between overweight (includes overweight and obesity) and/or wheeze at 16 years and $\mathrm{FEV}_{1} / \mathrm{FVC}(\%)$ at 16 years ( $n=1015$ girls and 840 boys). The point estimate represents mean difference in $\mathrm{FEV}_{1} / \mathrm{FVC}$ compared with the reference group (children with no overweight and no wheeze) calculated by linear regression adjusted for age and height. Children with thinness are excluded.

table 5), with significantly stronger associations among girls, compared with boys in the persistent overweight category ( $P$ value for interaction $<0.05)$. Transient overweight was not associated with $\mathrm{AX}^{0.5}$ or $\mathrm{R}_{5-20}$ at 16 years. There was no association between change in BMI status between 8 and 16 years and $\mathrm{FE}_{\mathrm{NO}}$. Persistent overweight between 8 and 16 years was however associated with higher blood neutrophil, but not eosinophil, cell count at 16 years (online supplementary table 5).

\section{DISCUSSION}

In the present study, we analysed longitudinal and cross-sectional associations between BMI status and lung function from 8 to 16 years among 2889 children from the BAMSE population-based birth cohort. The main analyses showed that overweight and

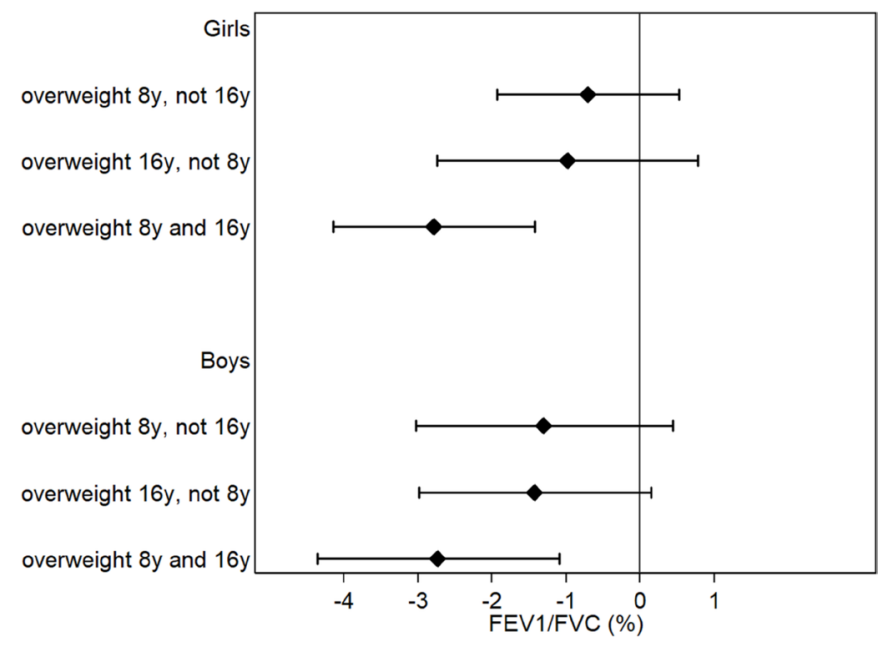

Figure 3 Associations between overweight (includes overweight and obesity) status between 8 and 16 years and FEV//FVC at 16 years ( $n=840$ girls and 720 boys). The point estimate represents mean difference in $\mathrm{FEV}_{1} / \mathrm{FVC}$ compared with the reference group (children with normal weight at 8 and 16 years) calculated by linear regression adjusted for age and height. Children with thinness are excluded. obesity were associated with evidence of airway obstruction (reduced $\mathrm{FEV}_{1} / \mathrm{FVC}$ ), but increased lung volume (FVC) and flow $\left(\mathrm{FEV}_{1}\right)$ up to 16 years, which is consistent with most previous studies on spirometry in children. ${ }^{4-12}$ Further, we found that overweight and obesity were associated with indications of peripheral airway obstruction as measured by the IOS technique in cross-sectional analyses, with stronger associations in girls, compared with boys. These results are novel and complement and strengthen our spirometry findings of airway obstruction (low $\mathrm{FEV}_{1} / \mathrm{FVC}$ ratio). In boys, obesity at 8 years was associated with further reduction in $\mathrm{FEV}_{1} / \mathrm{FVC}$ between 8 and 16 years, whereas in girls, there was no additional decrease from 8 to 16 years of age.

Forno et $\mathrm{al}^{14}$ showed that obesity is associated with airway dysanapsis and suggested that obesity is primarily related to anatomical and developmental airway obstruction that may not be related to airway inflammation or bronchospasm. ${ }^{14}$ In the present study, we observed similar associations with airway dysanapsis in cross-sectional analyses at 16 years. In line with their hypothesis, we found no association between BMI status and $\mathrm{FE}_{\mathrm{NO}}$. The results are consistent with previous cross-sectional studies, which have found no or negative associations between BMI and $\mathrm{FE}_{\mathrm{NO}}$ in children. ${ }^{129-31}$ Altogether, these findings suggest that obesity is associated with airway obstruction not driven by eosinophil airway inflammation.

Overweight and wheeze were both independently associated with lower $\mathrm{FEV}_{1} / \mathrm{FVC}$ in cross-sectional analyses at 16 years. Concomitant overweight and wheeze were associated with further reduction in $\mathrm{FEV}_{1} / \mathrm{FVC}$, but there was no significant interaction between overweight and wheeze, indicating that the association between overweight and $\mathrm{FEV}_{1} / \mathrm{FVC}$ does not differ by wheeze status. Also, adjusting for asthma or wheeze did not affect the observed cross-sectional associations between BMI status and lung function at 16 years, indicating that the results are not explained by asthma or asthma symptoms. Overweight and obesity were, however, associated with higher blood neutrophil cell count in cross-sectional analyses at 16 years, especially in girls. Obese asthma in children has previously been shown to mainly be non-eosinophilic in females but not in males. ${ }^{31}$ In adults, obesity has been associated with blood and sputum neutrophils in asthmatic women, but not men. ${ }^{32} 33$ No significant association was observed for eosinophils in these studies. Altogether, these results suggest that overweight and obesity in females are primarily associated with a neutrophilic, rather than eosinophilic, systemic inflammation, whereas findings are less clear for males. However, it should be noted that levels of both eosinophils and neutrophils were increased in obese girls in our study, indicating a general systemic inflammatory effect in these subjects.

The higher $\mathrm{R}_{5-20}$ and $\mathrm{AX}^{0.5}$ among overweight and obese individuals may be explained by compressed basal lung regions due to the increased abdominal volume. ${ }^{34}$ A compressed lung decreases compliance in the overall respiratory system, including the small airways. The larger lung volume among overweight and obese individuals would theoretically lead to lower resistance and greater compliance; however, this might not be the case as tidal breathing mainly involves the basal, more compressed, parts of the lung. ${ }^{35}$ For the same reason, $\mathrm{FEV}_{1} / \mathrm{FVC}$ might be lower among overweight and obese individuals as the expired air is coming from the compressed basal regions of the lung at the end of the forced expiration. The physiological impacts of obesity on lung function seem to be reversible, however, as bariatric surgery-induced weight loss has been shown to improve small airway function and $\mathrm{FEV}_{1} / \mathrm{FVC}$ in obese adult patients. ${ }^{36}$ Our longitudinal 
analyses on change in BMI status between 8 and 16 years showed that persistent, but not transient, overweight between 8 and 16 years was associated with airway obstruction at 16 years. These results build on to the Dutch PIAMA study which showed that persistent, but not transient, high BMI between 8 and 12 years was associated with reduced $\mathrm{FEV}_{1} / \mathrm{FVC}^{19}{ }^{19}$ From a public health perspective, these findings are important as they, again, indicate that obesity-related lung function reductions are reversible and highlight the importance of managing overweight and obesity as early as possible.

The strengths of the present study include the large population-based cohort with a high response rate, the repeated measurements of BMI status and spirometry and the assessment of lung function using both spirometry and IOS. This enabled us to perform longitudinal analyses, both analysing changes in BMI status and changes in lung function over time. Some potential limitations warrant mention. The majority of existing papers, including our present study, lack assessment of body composition but rather rely on BMI to define overweight and obesity. Although BMI, according to WHO, provides the most useful population-level measure of obesity, ${ }^{37}$ it cannot differentiate between lean and adipose tissue. During adolescence, increased BMI could to some extent reflect pubertal status and gain in lean mass, rather than fat mass. Pubertal status is also related to lung development. ${ }^{38}$ In our study, pubertal status was therefore evaluated as a potential confounder, but was not found to affect the results. Analysing body composition might yet provide more information about the obesity-lung function association, and local fat deposits such as visceral fat might, at least partly, drive the association between obesity and asthma. ${ }^{30}$ The adipose tissue secretes several different proinflammatory cytokines, which may explain this association; however, in the present study, we did not have information on these cytokines.

In the present study, there was no assessment of total lung capacity. In addition, asthma symptoms and medication were defined based on parental or adolescents' self-report. This might cause overestimation of the associations if overweight children are more observant about asthma symptoms, compared with normal weight children. Also, although several factors were evaluated as potential confounders, the observed associations might, as virtually always in observational studies, be influenced by residual or unmeasured confounding. Moreover, inflammation markers were only measured at 16 years of age, and no formal mediation analysis was performed to test whether these mediated the observed association between overweight/ obesity and lung function. Finally, although the participants were from a population-based cohort, selection bias cannot be ruled out as there were some differences between children who were included and not included in the analyses. In the present study, children who participated in the clinical investigation at 16 years had a slightly lower self-reported BMI than those only answering the questionnaire $\left(21.1 \mathrm{~kg} / \mathrm{m}^{2}\right.$ compared with $21.5 \mathrm{~kg} / \mathrm{m}^{2}$ ), which potentially could have led to an underestimation of the true association. In addition, the prevalence of overweight and obesity in our study population is somewhat lower compared with current national surveys in Sweden ${ }^{39}$ and the US. ${ }^{40}$

With a rising prevalence of obesity among children and adolescents, our results might have important clinical implications as childhood lung function is an essential determinant for adult lung function. ${ }^{41}$ Therefore, identifying modifiable risk factors, such as overweight and obesity, is important for prevention of impaired lung function and potentially, subsequent respiratory disease.

\section{CONCLUSION}

In childhood and adolescence, both overweight and obesity, and particularly persistent overweight, were associated with evidence of airway obstruction, including the small airways. Female overweight and obesity were further associated with increased circulating neutrophils. However, lung volumes and flows were in general higher in overweight compared with normal weight children, and the long-term impact of childhood obesity on respiratory health needs to be explored further.

Acknowledgements We thank all the participants in the BAMSE study as well as all the staff involved, especially Eva Hallner and Sara Nilsson. Statistician Niklas Andersson is also acknowledged for statistical support.

Contributors $E M, A B$ and IK are principal investigators of the BAMSE cohort. $\mathrm{SE}, \mathrm{AB}$ and EM designed the study. SE, JH, IK, JLPP, PT, PMG, AB and EM planned the analyses and interpreted the results. SE performed the statistical analyses and prepared the first manuscript draf. MB provided statistical expertise for the analyses. $\mathrm{SE}, J H, I K, J L P P, P T, M B, P M G, A B$ and EM critically revised the manuscript. All authors approved the final version of the manuscript.

Funding This work was supported by the Swedish Research Council (VR), the Stockholm County Council (ALF), the Swedish Heart and Lung Foundation, the Swedish Research Council for Health, Working Life and Welfare, the Swedish Asthma and Allergy Foundation, the European Commission's Seventh Framework 29 Program MeDALL under grant agreement no 261357, the Freemason Child House Foundation in Stockholm and the Swedish Research Council Formas.

Competing interests None declared.

Ethics approval Regional Ethical Review Board in Stockholm.

Provenance and peer review Not commissioned; externally peer reviewed.

Open Access This is an Open Access article distributed in accordance with the Creative Commons Attribution Non Commercial (CC BY-NC 4.0) license, which permits others to distribute, remix, adapt, build upon this work non-commercially, and license their derivative works on different terms, provided the original work is properly cited and the use is non-commercial. See: http://creativecommons.org/ licenses/by-nc/4.0/

(c) Article author(s) (or their employer(s) unless otherwise stated in the text of the article) 2018. All rights reserved. No commercial use is permitted unless otherwise expressly granted.

\section{REFERENCES}

1 World Health Organization. Obesity: preventing and managing the global epidemic: report of a WHO consultation. (WHO technichal report series 894). Geneva, Switzerland: World Health Organization, 2000:1-253.

2 McClean KM, Kee F, Young IS, et al. Obesity and the lung: 1. Epidemiology. Thorax 2008:63:649-54.

3 Umetsu DT. Mechanisms by which obesity impacts upon asthma. Thorax 2017:72:174-7.

4 Tantisira KG, Litonjua AA, Weiss ST, et al. Association of body mass with pulmonary function in the Childhood Asthma Management Program (CAMP). Thorax 2003;58:1036-41.

5 Bekkers MB, Wijga AH, de Jongste JC, et al. Waist circumference, BMI, and lung function in 8-year-old children: the PIAMA birth cohort study. Pediatr Pulmonol 2013;48:674-82

6 Chen Y, Rennie D, Cormier Y, et al. Waist circumference associated with pulmonary function in children. Pediatr Pulmonol 2009;44:216-21.

7 Chen YC, Huang YL, Ho WC, et al. Gender differences in effects of obesity and asthma on adolescent lung function: Results from a population-based study. J Asthma 2017:54:279-85.

8 Chu YT, Chen WY, Wang TN, et al. Extreme BMI predicts higher asthma prevalence and is associated with lung function impairment in school-aged children. Pediatr Pulmonol 2009;44:472-9.

9 Cibella F, Bruno A, Cuttitta G, et al. An elevated body mass index increases lung volume but reduces airflow in Italian schoolchildren. PLOS One 2015; 10:e0127154.

10 Davidson WJ, Mackenzie-Rife KA, Witmans MB, et al. Obesity negatively impacts lung function in children and adolescents. Pediatr Pulmonol 2014;49:1003-10.

11 Han YY, Forno E, Celedón JC. Adiposity, fractional exhaled nitric oxide, and asthma in U.S. children. Am J Respir Crit Care Med 2014;190:32-9.

12 Yao TC, Tsai HJ, Chang SW, et al. Obesity disproportionately impacts lung volumes, airflow and exhaled nitric oxide in children. PLoS One 2017;12:e0174691.

13 Forno E, Han YY, Mullen J, et al. Overweight, obesity, and lung function in children and adults-a meta-analysis. J Allergy Clin Immunol Pract 2017. 
14 Forno E, Weiner DJ, Mullen J, et al. Obesity and airway dysanapsis in children with and without asthma. Am J Respir Crit Care Med 2017;195:314-23.

15 McNulty W, Usmani OS. Techniques of assessing small airways dysfunction. Eur Clin Respir J 2014;1:25898.

16 Bickel S, Popler J, Lesnick B, et al. Impulse oscillometry: interpretation and practical applications. Chest 2014;146:841-7.

17 van der Wiel E, ten Hacken NH, Postma DS, et al. Small-airways dysfunction associates with respiratory symptoms and clinical features of asthma: a systematic review.J Allergy Clin Immunol 2013;131:646-57.

18 Takeda T, Oga T, Niimi A, et al. Relationship between small airway function and health status, dyspnea and disease control in asthma. Respiration 2010;80:120-6.

19 Bekkers MB, Wijga AH, Gehring U, et al. BMI, waist circumference at 8 and 12 years of age and FVC and FEV 1 at 12 years of age; the PIAMA birth cohort study. BMC Pulm Med 2015;15:39.

20 Ballardini N, Kull I, Lind T, et al. Development and comorbidity of eczema, asthma and rhinitis to age 12: data from the BAMSE birth cohort. Allergy 2012;67:537-44.

21 Wickman M, Kull I, Pershagen G, et al. The BAMSE project: presentation of a prospective longitudinal birth cohort study. Pediatr Allergy Immunol 2002;13(Suppl 15):11-13.

22 Cole TJ, Lobstein T. Extended international (IOTF) body mass index cut-offs for thinness, overweight and obesity. Pediatr Obes 2012;7:284-94.

23 Hallberg J, Thunqvist P, Schultz ES, et al. Asthma phenotypes and lung function up to 16 years of age-the BAMSE cohort. Allergy 2015;70:667-73.

24 Miller MR, Hankinson J, Brusasco V, et al. Standardisation of spirometry. Eur Respir J 2005;26:319-38.

25 Schultz ES, Hallberg J, Gustafsson PM, et al. Early life exposure to traffic-related air pollution and lung function in adolescence assessed with impulse oscillometry. J Allergy Clin Immunol 2016;138:930-2.

26 American Thoracic Society European Respiratory Society. ATS/ERS recommendations for standardized procedures for the online and offline measurement of exhaled lower respiratory nitric oxide and nasal nitric oxide, 2005. Am J Respir Crit Care Med 2005;171:912-30

27 Koenker R. Quantile regression. New York, NY: Cambridge University Press, 2005.

28 Quanjer PH, Stanojevic S, Cole TJ, et al. Multi-ethnic reference values for spirometry for the 3-95-yr age range: the global lung function 2012 equations. Eur Respir J 2012;40:1324-43
29 Casas M, den Dekker HT, Kruithof CJ, et al. Early childhood growth patterns and school-age respiratory resistance, fractional exhaled nitric oxide and asthma. Pediatr Allergy Immunol 2016;27:854-60.

30 den Dekker HT, Ros KPI, de Jongste JC, et al. Body fat mass distribution and interrupter resistance, fractional exhaled nitric oxide, and asthma at school-age. $J$ Allergy Clin Immunol 2017;139:810-8.

31 Jensen ME, Gibson PG, Collins CE, et al. Airway and systemic inflammation in obese children with asthma. Eur Respir J 2013;42:1012-9.

32 Scott HA, Gibson PG, Garg ML, et al. Airway inflammation is augmented by obesity and fatty acids in asthma. Eur Respir J 2011;38:594-602.

33 Telenga ED, Tideman SW, Kerstjens HA, et al. Obesity in asthma: more neutrophilic inflammation as a possible explanation for a reduced treatment response. Allergy 2012;67:1060-8.

34 Gronkvist M, Bergsten E, Eiken 0, et al. Inter- and intraregional ventilation inhomogeneity in hypergravity and after pressurization of an anti-G suit. J App/ Physiol 2003;94:1353-64.

35 Bryan AC, Milic-Emili J, Pengelly D. Effect of gravity on the distribution of pulmonary ventilation. J Appl Physiol 1966;21:778-84.

36 van Huisstede A, Rudolphus A, Castro Cabezas M, et al. Effect of bariatric surgery on asthma control, lung function and bronchial and systemic inflammation in morbidly obese subjects with asthma. Thorax 2015;70:659-67.

37 World Health Organization. Obesity and overweight: fact sheet N0 311 [Internet: World Health Organization, 2012. http://www.who.int/mediacentre/factsheets/fs311/ en/index.html (cited 30 Jun 2017).

38 Nève V, Girard F, Flahault A, et al. Lung and thorax development during adolescence: relationship with pubertal status. Eur Respir J 2002;20:1292-8.

39 The Public Health Agency of Sweden. Övervikt och fetma - nationella resultat och tidsserier 2016. The Public Health Agency of Sweden 2016. https://www. folkhalsomyndigheten.se/folkhalsorapportering-statistik/statistikdatabaser-ochvisualisering/nationella-folkhalsoenkaten/levnadsvanor/overvikt-och-fetma/ (cited 2017 June 30)

40 Ogden CL, Caroll MD, Fryar CD, et al. Prevalence of Obesity Among Adults and Youth: United States, 2011-2014. NCHS Data Brief 2015;219:1-8.

41 Melén E, Guerra S. Recent advances in understanding lung function development. F1000Res 2017;6:726. 